\title{
Demythification of anxiety and sleep problems in older women
}

\author{
Anagha Tendulkar ${ }^{1}$, Jennie Mendes ${ }^{2}$ \\ ${ }^{1}$ Assistant Professor, Department of Sociology, ${ }^{2}$ Associate Professor, Department of Psychology \\ Sophia College for Women, Mumbai. \\ Corresponding author: Ms. Anagha Tendulkar \\ Email: anaghatendulkar@gmail.com
}

\begin{abstract}
Background: This study attempts to isolate anxiety as a singular variable influencing sleep in elderly women. Later life anxiety is an understudied area. Older adults living alone in their houses have more responsibility and therefore more anxiety. Sleep problems are not a result of aging. Nearly half of the population of senior citizens report sleeps disturbances.

Methods: Thirteen elderly women living alone in the age group of 75 to 93 from three Goan villages were studied. Face to face semi-structured interviews using Hamilton anxiety rating scale (HARS-R), Hamilton Depression rating scale (HDRS-R), and the Pittsburg Insomnia scale were used. Health history, medication and activity information was obtained.

Results: Results supported previous studies done. Insomnia and anxiety are significantly related with a control for depression. Anxiety and activity are significant predictors of insomnia The causal nature between the variables are unexplained.

Conclusion:An important implication in this study is to identify a clear etiology so that insomnia can be treated in senior citizens.
\end{abstract}

Keywords: Ageing women, Insomnia Anxiety, Depression, Activity, Medication.

(Paper received $-28^{\text {th }}$ December 2017, Peer review completed $-10^{\text {th }}$ January 2018)

(Accepted $-12^{\text {th }}$ January 2018)

\section{INTRODUCTION}

Demographic Ageing, popularly known as Population Ageing is an empirical reality of developed societies of the Western global region; and is gradually emerging to be an inevitable part of the demographic fabric of developing societies. The gravity of implications of demographic aging are most undocumented in academic discourses of social and psychological Gerontology. A concomitant sub process within the bigger process of demographic aging is that of Feminization of Aging. It implies elderly women being more in number than the elderly men in a given societal set up. The phenomenon of gender- specific process of aging is not deliberated upon much so as to give justice to its exclusive and specific character. Increasing number of elderly women constitute this rapidly growing category. The category certainly merits academic attention; however, there is paucity of reliable and valid data on this phenomenon.

Longevity is understood as a desirable indicator of development. However not the length but the quality of life is an important criterion to understand satisfaction in older persons. Quality of life is an individual's satisfaction or happiness with life in domains he or she considers important [1]. There are several indicators to gauge quality of life. Physical well-being is undoubtedly one of them. Physical well-being in the older person is affected by several factors. Lack of adequate sleep is one of it. Inadequate sleep can cause tiredness, lack of mindfulness, and general irritability. All these features in the old go undetected, and insomnia is taken as a given condition positively correlated with ageing [2]. 
Sleep is a very sensitive state easily affected by ones health, medicine intake, one's self help skills sedentariness and overall happiness and satisfaction in life. The aged show many symptoms of anxiety, depression triggered by their fear of illness, loneliness and death anxiety. Such anxious thoughts cause wakeful nights. Many studies between 1995 and 2005 have shown inconsistencies and opposing findings regarding gender and sleep difficulties [3]. Therefore, the current investigation focused on women only living alone in their homes independently. 40 to $50 \%$ of the older population has sleep complaints. It is important to note that sleep difficulties are common to the old but are not the natural result of ageing, but is because of the decreased ability rather than the decreased need to sleep [4].

Sleep allows the brain to rest. We spend $1 / 3^{\text {rd }}$ of our lives sleeping. Many brain areas are involved like the suprachiasmatic nucleus in the hypothalamus, brain stem; thalamus, cerebral cortex, forebrain, midbrain pineal gland and amygdale are all active during sleep. New-borns sleep 18 hours, followed by teens who need around 9 hours. Most adults need around 7 hours. Senior citizens sleep lesser as they are interrupted by the need to use the toilet due to medicines like diuretics stimulants and other drugs they use. That may likely interrupt sleep. Also, medical conditions like Diabetes mellitus, arthritis. Parkinson's disorder, asthma, renal failure, and pain, itching coughing may cause sleep problems. Therefore, sleep problems should not be accepted as normal givens.

According to the National Institute of Neurological Disorders and stroke research (Brain resources and information network BRAIN) Sleep consists of the following 4 stages:

1. Non Rapid Eye Movement (NREM) is a few minutes of light sleep with slow brain waves

2. NREM stage where the brain waves slow down further but are interspersed by bursts of spikes. Maximum sleep time is spent in this stage.

3. NREM stage is deep sleep with very slow waves

4. Rapid Eye Movement (REM) is a 90 minutes stage with mixed brain waves. Dreaming and memory consolidation takes place in this stage.

Caregivers, relatives and old age institution staff are always ignoring sleep difficulties in the aged thereby lessening their quality of life (Mendes in press) Psychologists must strive to understand problems in daily living among the older adults [5].

The percent of people showing lifetime prevalence of anxiety has a sharp decline in persons 60 years and older [6]. The anxiety manifested by the elderly does not have a specific form, here worry is a constant feature in their day to day existence [7].

Women are $70 \%$ more likely than men to experience depression in their lives [5,8]. People assume that anxiety and depression is a package of ageing. Late life depression is not a norm. Advancing age does give rise to loss of support, job and relatives due to their deaths. Symptoms of depression such as sadness, loss of joy in things that earlier gave happiness, loss of energy which makes them report tiredness. This is further accompanied by thoughts of being useless and life being hopeless. Concentration and decision making gets affected. The 1999 Surgeon General's Report on Mental Health revealed that almost 20\% of older adults, experience depression, although not the most prevalent mental disorder among older adults, is a very significant source of suffering. From a clinical perspective, it is a particularly complex and challenging phenomenon, due in part to age-related differences in the experience and presentation of depressive symptoms, risk factors, and the many potential causes of depressive symptoms Depression in older adults is often overestimated and under recognized, and it is not the most prevalent psychiatric disorder among older adults, as many believe [8].

This study attempts to isolate anxiety as a singular variable influencing sleep in elderly women. Later life anxiety is an understudied area. Older adults living alone in their houses have more responsibility and therefore more anxiety. Sleep problems are not a result of aging. Nearly half of the population of senior citizens report sleeps disturbances. There is a decrease in the ability to sleep but not a decrease in the need for sleep as it is often made out to be. 


\section{METHODOLOGY}

A of 13 elderly women living alone in the age group of 75 to 93 from three Goan villages were interviewed. This involved 3 home visits of approximately 45 to 55 minutes to collect both qualitative and quantitative data for each participant.

A general health rating was obtained. Work amount and amount of walking and activity were taken as indicators of physical activity and rated as physical activity level. The Hamilton Depression Rating Scale HDRS (also known as the Ham-D) [9] is the most widely used clinician-administered depression assessment scale. The original version contains 17 items (HDRS-17) pertaining to symptoms of depression experienced over the past week.

The Pittsburgh Sleep Questionnaire Inventory PSQI [10] is a 19-item questionnaire evaluating sleep quality and disturbances over the past month. The first 4 items are open questions, whereas items 5 to 19 are rated on a 4-point Likert scale. Individual items scores yield 7 components. A total score, ranging from 0 to 21 , is obtained by adding the 7 component scores. A score $>5$ suggests poor sleep quality. The psychometric properties of the PSQI have been documented in multiple studies, including one with a French-Canadian sample. The PSQI was used because it measures a construct (sleep quality) that is related to insomnia but a construct that is broader than insomnia severity.

The State Trait Anxiety Inventory STAI is a 2-part instrument assessing state (situational) and trait anxiety (in general). Only the Trait part (STAI-Trait) was used in the present study. The STAI-Trait comprises 20 items rated on a 4-point Likert scale. Psychometric properties of the STAI are excellent [11].

\section{STATISTICAL ANALYSIS}

1. Hierarchical Regression: To investigate the relationship between anxiety and insomnia The criterion variables were Insomnia score with a predictors a-Depression b-Activity time c. amount of Medications $d$. anxiety e-medical issues

2. Pearson bivariate correlation: i-medication and insomnia ii- activity amount and insomnia

3. Correlation: Correlation between activity, Total medications was correlated with Depression anxiety and Insomnia

Based on self reports the general heath, medications take and amount of physical activity was rated

\section{RESULTS}

Table 1 - Pearsons Bivariate Correlations

\begin{tabular}{|c|c|c|c|c|c|}
\hline & Activity & Medication & Anxiety & Depression & Insomnia \\
\hline Anxiety & $-0.38^{*}$ & $+0.22^{*}$ & - & $+0.40^{*}$ & $-0.50^{*}$ \\
\hline Depression & $-0.61^{*}$ & $+0.39^{*}$ & - & - & $+0.33^{*}$ \\
\hline Insomnia & $-0.44^{*}$ & $+0.27^{*}$ & - & - & \\
\hline \multicolumn{5}{|c}{$\mathrm{p}<0.01$ (significant) } \\
\hline
\end{tabular}

Table 2 - Summary of Hierarchical Regression Analysis for Variables Predicting Insomnia

\begin{tabular}{|l|l|l|l|l|}
\hline & B & SEb & B & R2 \\
\hline Step one 2 characteristics & $0.29^{* *}$ \\
\hline Activity & -2.11 & 0.64 & $-0.40^{* *}$ & \\
\hline Medications & 0.09 & 0.23 & 0.09 & \\
\hline Depression & 0.07 & 0.31 & 0.03 & \\
\hline Step two Anxiety \\
\hline Anxiety & 0.26 & 0.09 & $0.34^{* *}$ & $0.31^{* *}$ \\
\hline Change in R2 \\
\hline
\end{tabular}

( ${ }^{*} p<0.05^{* *} p<0.01-$ significant) 


\section{DISCUSSION}

There was a significant relationship between anxiety and insomnia after controlling for depression. Depression stands as a distinct variable. This finding is in line with literature showing such a relationship. Anxiety was a predictor for insomnia so was Physical activity levels. Higher activity was negatively associated with lower reported symptoms of insomnia It is known that medications have an effect on sleep quality and quantity.

One implication of this study is that there is a clear differentiation between anxiety and depression. Older women must maintain low or anxiety free lifestyle in order to sleep well. This can be done by increasing physical activity and decreasing the number of medicines taken.

The macro level implication of the study has a bearing on the quality of geriatric care giving system. Women living alone tend to feel lonely as well. The self-care is also perceived as a burden. Moreover, there exist economic pressure like health care expenses, limited investments and cultural hurdles like widowhood, alienation etc. The perceived insecurity results in marginalization. A sense of exclusion particularly in elderly women who live alone generates anxiety. In order to mitigate the problem strategic and planned intervention is a plausible solution.

It must be noted that a more sensitive case specific approach for meaningful intervention is a requirement since standardization of solutions could defeat the very purpose of the study.

This study with a similar approach needs to be replicated with a larger sample of women to attain a larger picture of the variability of the problem. The urban and rural divide should also be considered while conducting a similar study. Moreover, a separate study with a similar paradigm should also be conducted on women living in old age institutions in order to understand their problems better.

\section{REFERENCES}

1. Sharma KL. Dimensions of Ageing: Indian studies, Rawat Publications ; 2009.

2. Kolb B, Whishaw IQ. Fundamentals of human neuropsychology. Macmillan; 2009.

3. Heaton K, Anderson D. A psychometric analysis of the Epworth Sleepiness Scale. J Nurs Measure 2007;15(3):177-88.

4. Reid KJ, Martinovich Z, Finkel S, Statsinger J, Golden R, Harter K, Zee PC. Sleep: a marker of physical and mental health in the elderly. Am J Geriatr Psychiatry 2006;14(10):860-6.

5. American Psychological Association. Guidelines for Psychological practices with older adults. APA; 2004.

6. Kessler RC, Berglund P, Demler O, Jin R, Merikangas KR, Walters EE. Lifetime prevalence and age-ofonset distributions of DSM-IV disorders in the National Comorbidity Survey Replication. Arch Gen Psychiatry 2005;62(6):593-602.

7. Halgin R, Whitbourne SK. Abnormal Psychology: Clinical perspectives on psychological disorders. Pearson ;2009.

8. Gopal M. Gender, ageing and social security. Economic and Political Weekly 2006;21:4477-86.

9. Williams JB. A structured interview guide for the Hamilton Depression Rating Scale. Arch Gen Psychiatry 1988;45(8):742-7.

10. Buysse DJ, Reynolds CF, Monk TH, Berman SR, Kupfer DJ. The Pittsburgh Sleep Quality Index: a new instrument for psychiatric practice and research. Psychiatr Res 1989;28(2):193-213.

11. Spielberger CD. Sate-Trait Anger Expression Inventory-2: STAXI-2. PAR, Psychological Assessment Ressources; 1999.

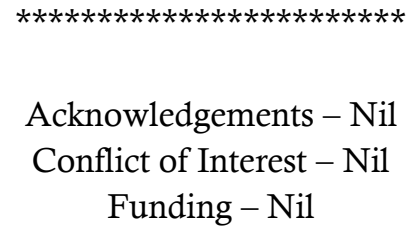

